\title{
Analisis Penyimpanan Produk Menggunakan Metode Shared Storage (Studi Kasus di PT. X)
}

\author{
Candrianto $^{1}$, Wahyuni Amalia ${ }^{1}$, Habib Syafira Ramadhan ${ }^{1}$ \\ ${ }^{1}$ Program Studi Manajemen Logistik Industri Agro, Politeknik ATI Padang, Bungo Pasang Tabing Padang 25171 Indonesia
}

\section{ARTICLE INFORMATION}

Received: December 08, 2020

Revised: December 21, 2020

Available online: December 31, 2020

\section{KEYWORDS}

Layout, Shared Storage, Warehouse

\section{CORRESPONDENCE}

Name: Candrianto

E-mail: candriantokemenperin@gmail.com

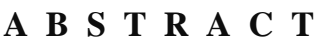

PT. X is a company engaged in shipping services. This company has a spare part storage warehouse that is not yet effective and efficient. This can be seen from the placement of items that are not suitable and require a long time in the process of picking up goods. This study aims to redesign the layout of the storage warehouse using the shared storage method. Shared storage is a method of arranging a storage area based on the warehouse floor area by placing the items that are sent immediately closest to the door, and so on. This method uses the FIFO (first in first out) principle so that the outbound process is easier and takes less time to search for goods. Based on the processing using the shared storage method, a proposal is made to improve the layout by adding 2 storage racks arranged by product type. The previous pallet 1210 became 3234. Forging of storage racks takes into account the size of the demand, so that products with more demand are placed in the area close to the door. With this, there are no more products stored in any area, and product collection will be easier and faster.
\end{abstract}

\section{PENDAHULUAN}

Gudang merupakan area yang sangat penting dalam menunjang aktivitas di suatu perusahaan. Tidak hanya berfungsi sebagai tempat penyimpanan, peningkatan produktivitas dan pelayanan pergudangan akan sangat berpengaruh pada performansi perusahaan secara keseluruhan [2]. Salah satu yang berpotensi meningkatkan performansi pergudangan adalah penataan tata letak Gudang yang efektif. Penataan tata letak memberikan banyak dampak strategis karena sangat menentukan daya saing perusahaan meliputi kapasitas, proses, fleksibilitas, biaya, kualitas lingkungan kerja, hubungan dengan pelanggan, serta citra perusahaan [5].

Terdapat banyak aktivitas yang dilakukan di Gudang, mulai dari inbound sampai outbound logistik. Kelancaran aktivitas yang ada digudang sangat bergantung pada tata letak gudang. Penataan yang tidak tepat dapat menghambat aktivitas-aktivitas yang ada digudang, mengurangi performansi kerja, meningkatkan kesalahan kerja dan berpotensi terjadinya kecelakaan kerja. Heizer dan Render mengatakan,tata letak gudang adalah sebuah desain yang mencoba meminimalkan biaya total dengan mencapai panduan yang terbaik antara luas ruang dan penanganan bahan [3]. Tujuan tata letak gudang adalah untuk menemukan titik optimal diantara biaya penanganan bahan dan biaya-biaya yang berkaitan dengan luas ruang dalam gudang. Sebagai konsekuensinya, tugas manajemen adalah memaksimalkan penggunaan setiap kotak dalam gudang yaitu memanfaatkan volume penuhnya sambil mempertahankan biaya penanganan bahan yang rendah. Biaya penanganan bahan adalah biaya-biaya berkaitan dengan transportasi barang masuk, penyimpanan, dan transporasi bahan yang keluar untuk dimasukan dalam gudang.

Banyak hal yang perlu dipertimbangkan dalam membuat tata letak Gudang diantaranya jenis barang yang disimpan, volume input, volume permintaan, jenis material handling yang digunakan dan jumlah karyawan [10]. Dalam perencanaan tata letah Gudang terdapat 13 aspek penting yang perlu dipertimbangkan, yaitu produk, ukuran produksi, luas ruangan, peralatan/mesin, perbaikan dan penggantian, keseimbangan kapasitas, pemindahan minimum, aliran 
material, area karyawan, area pelayanan, area tunggu, kelembaban ruangan, dan fleksibilitas [9].

Dalam penataan tata letak Gudang, bagian yang penyiampanan merupakan area yang yang sangat penting. Terdapat 4 metode yang dapat digunakan untuk mengatur lokasi penyimpanan [8]:

\section{1) Metode Dedicated Storage}

Metode ini sering disebut sebagai penyimpanan yang sudah tertentu dan tetap karena lokasi untuk tiap barang sudah ditentukan tempatnya. Jumlah lokasi penyimpanan untuk suatu produk harus dapat mencukupi kebutuhan ruang penyimpanan yang paling maksimal dari produk tersebut. Ruang penyimpanan yang diperlukan adalah kumulatif dari kebutuhan penyimpanan maksimal dari tiap jenis produknya jika produk yang akan disimpan lebih dari satu jenis.

\section{2) Metode Randomized Storage}

Metode ini sering disebut dengan floating lost storage, yaitu penyimpanan yang memungkinkan produknya disimpan berpindah lokasi penyimpanannyasetiap waktu. penempatan barang hanya memperhatikan jarak terdekat menuju suatu tempat penyimpanan dengan perputaran penyimpanannya menggunakan sistem FIFO (First In Frist Out). Faktor- faktor lain seperti jenis barang yang disimpan, dimensi, dan jaminan keamanan barang kurang diperhatikan. Hal ini membuat penyimpanan barang menjadi kurang teratur.

\section{3) Metode Class-Based Storage}

Metode class-based storage ini merupakan kebijakan penyimpanan yang membagi barang menjadi tiga kelas A, B, dan C berdasarkan pada hukum pareto dengan memperhatikan level aktivitas storage dan retrival (S/R) dalam gudang. Metode ini membuat pengaturan tempat dirancang lebih fleksibel yaitu dengan cara membagi tempat penyimpanan menjadi beberapa bagian. Tiap tempat tersebut dapat diisi secara acak oleh beberapa jenis barang yang telah diklasifikasikan berdasarkan jenis maupun ukuran dari barang tersebut.

\section{4) Metode Shared Storage}

Metode ini merupakan variasi dari dedicated strorage sebagai jalan keluar untuk mengurangi kebutuhan ruang penyimpanan dengan penentuan produk secara lebih hati-hati terhadapruang yang dipakai. Produk yang berbeda menggunakan slot penyimpanan yang sama, walaupun hanya satu produk yang menenmpati satu slot pada saat slot terisi. Metode shared storage berkenaan dengan lokasi yang bergantung pada munculnya tempat kososng dalam Gudang. Metode ini cocok dugunakan jika produk yang disimpan bermacam-macam jenisnya dengan permintaan yang relative konstan. Untuk mendukung pertimbangan atas shared storage, jika kedatangan dari 100 palet dengan jumlah besar "perpindahan yang cepat" dari produk untuk disimpan. Palet dengan jumlah besar tersebut akan digunakan kembali dan akan dikirim sebanyak 5 palet per hari dalam rntang waktu 20 hari. Kelebihan metode ini yaitu barang yang dipesan dalam jumlah banyak memudahkan dalam proses Outbound dan tidak memakan waktu yang lama dalam proses pencarian barang. Sedangkan kekurangan metode ini yaitu harus membuat rak yang banyak dan disusun secara detail yang nantiya akan mengganggu proses kerja dan mengeluarkan dana yang cukup banyak bagi perusahaan.

\section{Pemindahan Bahan}

Proses pemindahan barang dapat dilakukan secara manual maupun menggunakan material handling. Barang dipindahkan dari titik awal ke titik tujuan. Apabila terdapat dua buah stasiun kerja/departemen I dan $\mathrm{j}$ yang koordinatnya ditunjukan sebagai $(\mathrm{x}, \mathrm{y})$ dan (a,b), maka untuk menghitung jarak antar dua titik tengah dij dapat dilakukan beberapa metode, yaitu:

\section{1) Rectilinear Distance}

Jarak di ukur sepanjang lintasan dengan menggunakan garis tegak lurus satu dengan yang lainnya. Sebagai contoh adalah material yang berpindah sepanjang gang (aisle) rectilinier dipabrik.

$\mathbf{d i j}=|\mathbf{x}-\mathbf{a}|+|\mathbf{y}-\mathbf{b}|$

\section{2) Euclidean Distance}

Jarak diukur sepanjang lintasan garis lurus antara dua buah titik. Jarak euclidean dapat diilustrasikan sebagai conveyor lurus yang memotong dua buah stsiun kerja.

$\operatorname{dij}=\sqrt{ }\left[(\mathbf{x} 2-\mathrm{x} 1)^{2}+(\mathbf{y} 2-y 1)^{2}\right]$

\section{3) Squared Euclidean Distance}

Jarak diukur sepanjang lintasan sebenarnya yang melintas antara dua buah titik. Sebagai contoh pada sistem kendaraan terkendali (guided vehicle system), kendaraan pada perjalananya harus mengikuti arah-arah yang sudah ditentukan pada jaringan lintasan terkendali. Oleh karena itu, jarak lintasan aliran bisa lebih panjang dibandingkan dengan rectilinier atau Euclidean.

$$
\operatorname{dij}=(x-a)^{2}+(y-b)^{2}
$$

PT. X merupakan perusahan yang bergerak pada jasa pengiriman barang. Barang yang akan dikirim datang dan disimpan di Gudang. Pada saat proses penyim[anan, terjadi beberapa permasalahan seperti barang tidak diletakkan sesuai jenisnya serta melebihi kapasitas penyimpanannya. Hal ini mengakibatkan terganngunya proses kerja di Gudang dan pengiriman barang tidak 
efisien serta membutuhkan waktu yang cukup lama untuk mengambil produk yang dipesan.

Dari permasalahan tersebut perlu dilakukan perancangan ulang tata letak Gudang, sehingga proses penyimpanan lebih efektif dan memudahkan dalam pencarian barang. Adapun tujuan dari penelitian ini adalah memberikan usulan tata letak penyimpanan produk di PT. X menggunakan metode shared storage. Metode ini sudah banyak digunakan pada penelitian terdahulu. Salah satunya penelitian yang dilakukan oleh Zaenuri yang menggunakan metode ini untuk mengurangi jarak dari tempat penyimpanan [6]. Metode Shared Storage juga dapat dikombinasikan dengan metode lainnya, seperti yang dilakukan oleh Moengin dkk. yang memilih usulan tata letak gudang menggunakan metode Benferroni setelah sebelumnya menggunakan shared storage [7].

Selain menggunakan metode shared storage, terdapat metode lain yang bisa digunakan dalam re-layout pabrik ataupun Gudang. William melakukan perancangan tata letak Gudang menggunakan metode Activity Relationship Chart yang menggunakan tolak ukur dari kedekatan hubungan objek [11]. Nur \& Maarif mengkombinasikan metode clased based storage dengan CRAFT (Computerized Relative Allocation of Facilities Technique) [4].

Metode tata letak penyimpanan shared storage didasarkan pada banyaknya aktivitas keluar masuk produk dengan jarak tempuh terpendek terhadap titik input/output. Keuntungan metode ini bagi perusahaan yaitu proses pencarian barang menjadi lebih mudah karena tiap jenis barang berada pada suatu area yang sama. Selain itu barang dengan frekuensi tinggi juga lebih mudah dicari sehingga menyebabkan proses pencarian menjadi lebih cepat

\section{METODOLOGI}

Penelitian dilakukan pda PT. X khususnya dibagian inbound, putaway dan outbound barang yang ada digudang. Data dikumpulkan melalui penelitian secara langsung dilapangan, data sekunder, wawancara dan studi Pustaka. Metode analisis yang digunakan yaitu metode shared storage, dengan Langkah-langkah sebagai berikut:

1. Membuat layout penyimpanan awal

2. Penentuan tata letak dengan metode shared storage

3. Pembuatan layout baru

4. Membandingkan layout lama dan layout baru Tahapan pengolahan data terlihat seperti Gambar 1 berikut:

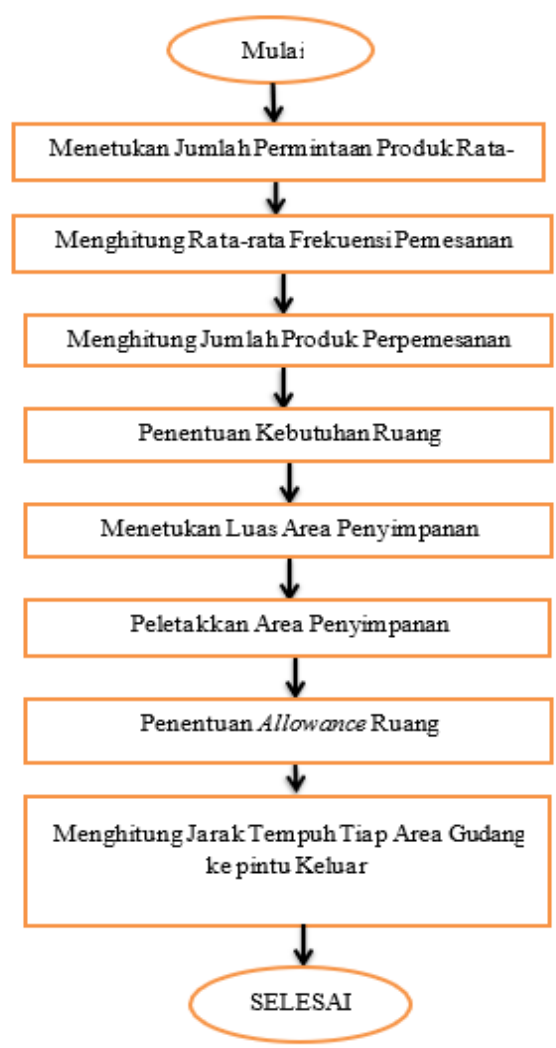

Gambar 1. Tahapan Pengolahan Data

\section{HASIL DAN PEMBAHASAN}

PT. X memiliki Gudang dengan luas sebesar $1500 \mathrm{~m}^{2}$, jumlah pallet 1210 dan area parkir $900 \mathrm{~m}^{2}$. Area Pergudangan pada PT. X terlihat seperti Gambar 2 berikut:

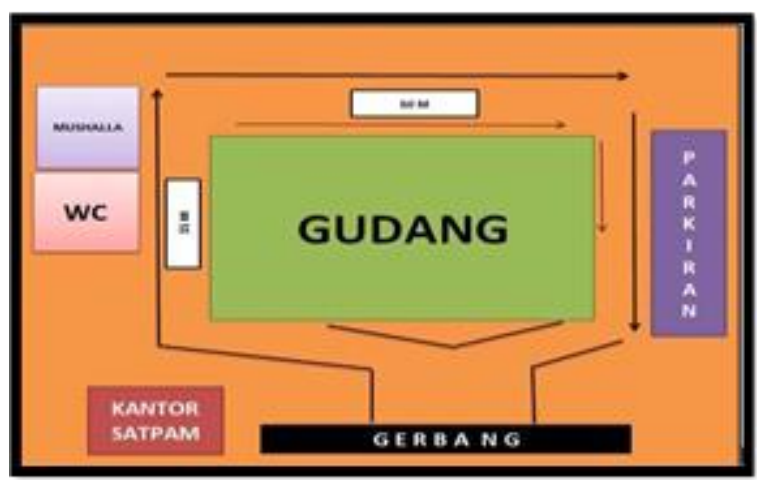

Gambar 2. Gudang PT. X

PT. X memiliki tenaga kerja Gudang sebanyak 23 orang dengan jadwal kerja senin sampai sabtu, masuk pada pukul 08.30 dan keluar pada pukul 13.00. Terdapat 5 jenis produk (spare part mobil) yang disimpan di Gudang PT. X, yaitu setir, Baut, Spion, lampu dan safety belt. Semua barang tersebut disimpan di rak. Susunan rak di Gudang terdiri dari 5 area, masing masing area memiliki $10 \mathrm{rak}$, setiap rak terdapat 50 pallet. 


\section{Penerimaan dan Pengeluaran Produk}

Data yang di peroleh dari gudang adalah data inbound dan data outbound produk selama 6 bulan pada gudang PT. X dapat dilihat pada Tabel 1.

Berdasarkan data pada Tabel 1, penerimaan paling banyak terjadi pada prosuk baut di bulan November sebesar 9930 kardus. Sebaliknya, penerimaan produk yang paling sedikit terjadi pada bulan September untu produk safety belt sebesar 97 kardus. Kapasitas penyimpanan barang pada Gudang PT. X adalah 1210 pallet per hari.

Tabel 1. Data Penerimaan dan Pengeluaran PT. X selama 6 bulan

\begin{tabular}{ccccccccc}
\hline $\begin{array}{l}\text { Produk } \\
\text { (kardus) }\end{array}$ & Ket. & Juni & Juli & Agustus & September & Oktober & November & TOTAL \\
\hline Baut & In & 1580 & 1650 & 1780 & 1645 & 1920 & 9930 & 18505 \\
& Out & 1560 & 1550 & 1520 & 1620 & 1890 & 1886 & 10026 \\
Safety Belt & In & 135 & 154 & 168 & 97 & 188 & 137 & 879 \\
& Out & 120 & 145 & 160 & 90 & 176 & 137 & 828 \\
Setir & In & 1356 & 1280 & 1289 & 2198 & 1881 & 1752 & 9756 \\
& Out & 1200 & 1245 & 1250 & 2190 & 1789 & 1657 & 9331 \\
Spion & In & 1210 & 1376 & 1296 & 1654 & 1228 & 1342 & 8106 \\
& Out & 1100 & 1268 & 1287 & 1542 & 1128 & 1243 & 7568 \\
Lampu & In & 1765 & 1678 & 1534 & 1689 & 1662 & 1226 & 9554 \\
& Out & 1623 & 1650 & 1510 & 1654 & 1552 & 1126 & 9115 \\
\hline
\end{tabular}

Sumber: PT. X

\section{Menentukan Jumlah Rata-rata Permintaan Per Bulan}

Data yang diambil untuk menentukan rata-rata permintaan perbulan adalah jumlah barang keluar untuk masing-masing produk selama 6 bulan. Berdasarkan hasil perhitungan, maka didapatkanlah jumlah rata-rata permintaan perbulan untuk masing-masing produk seperti terlihat pada Tabel 2.

Tabel 2. Jumlah permintaan Rata-rata per Bulan

\begin{tabular}{cc}
\hline Jenis produk & $\begin{array}{c}\text { Jumlah permintaan Rata- } \\
\text { rata/bulan (Kardus) }\end{array}$ \\
\hline Baut & 1671 \\
Safety Belt & 138 \\
Setir & 1555 \\
Spion & 1261 \\
Lampu & 1519 \\
\hline
\end{tabular}

Sumber: PT. X

\section{Rata-Rata Frekuensi Pemesanan PT. X Tahun 2019}

Frekuensi pemesanan yang dilakukan perusahaan mulai dari bulan Juli-Novenber 2019 untuk masing-masing produk terlihat seperti Gambar 3.

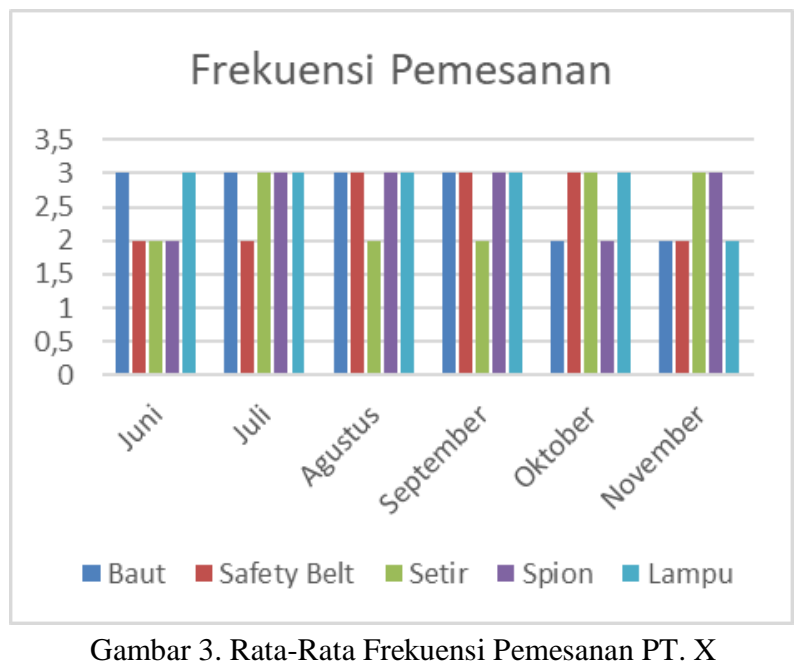

Pada Gambar 3 dapat dilihat bahwa permintaan produk perbulan yaitu naik turun. Pada tiap bulan permintaan terendah sebanyak 2 kali dan perminatan terbanyak 3 kali. Jadi rata-rata permintaan semua produk perbulan sebanyak 3 kali.

\section{Jumlah Produk Per Pemesanan Tiap Jenis Produk Per Bulan}

Setelah mengetahui jumlah rata-rata frekuensi perbulan maka dapat ditentukan jumlah produk tiap pemesanan untuk masing produk, seperti terlihat pada Tabel 3. 
Tabel 3. Jumlah Produk Per Pemesanan Tiap Jenis Produk Perbulan

\begin{tabular}{lccc}
\hline Produk & $\begin{array}{c}\text { Jumlah } \\
\text { Permintaan } \\
\text { Rata-rata } \\
\text { Perbulan }\end{array}$ & $\begin{array}{c}\text { Rata-rata } \\
\text { Frekuensi } \\
\text { Permintaan } \\
\text { per bulan }\end{array}$ & $\begin{array}{c}\text { Jumlah } \\
\text { Produk } \\
\text { 1 kali } \\
\text { pesan } \\
\text { (kardus) }\end{array}$ \\
\hline Baut & 1671 & 3 & 557 \\
Safety Belt & 138 & 3 & 46 \\
Setir & 155 & 3 & 518 \\
Spion & 1261 & 3 & 420 \\
Lampu & 1519 & 3 & 506 \\
\hline
\end{tabular}

\section{Kebutuhan Ruang}

Dilihat lamanya waktu antara penyimpanan dengan tanggal pengiriman agar barang dalam gudang dapat terjadwal dengan baik, dan lamanya waktu antara penyimpanan dengan tanggal pengiriman dapat ditentukan sebagai lamanya satu jenis produk berada di dalam gudang produk jadi. Lama rata-rata waktu awal penyimpanan sampai dikrim dapat dilihat pada Tabel 4 .

Tabel 4. Rata-Rata Waktu penyimpanan

\begin{tabular}{lc}
\hline \multicolumn{1}{c}{ Produk } & $\begin{array}{c}\text { Rata-rata } \\
\text { Penyimpanan (hari) }\end{array}$ \\
\hline Baut & 13 \\
Safety belt & 12 \\
Setir & 13 \\
Spion & 12 \\
Lampu & 11 \\
\hline
\end{tabular}

Sumber: PT. X

Waktu penyimpanan terbesar adalah 13 hari dan kapasitas penyimpanan perhari yaitu 110 pallet, maka dibutuhkan ruang untuk penyimpanan 13 hari yaitu lead time dikali kapasitas penyimpanan perhari $=13 \times 110$ pallet adalah 1430 pallet.

\section{Penentuan Luas Area Penyimpanan yang Diperlukan}

Pada satu rak terdiri dari 50 pallet produk yang mana 1 pallet terdiri dari 100 kardus. Dengan menggunakan penyusunan dengan luas area yang tersedia $1500 \mathrm{~m} 2$ Dilakukan untuk mempermudah dalam penyusunan produk dan menghemat penyimpanan dan menghemat pemanfaatan ruang. Banyaknya area penyimpanan yang dibutuhkan adalah:

Kebutuhan Area Penyimpanan $=\frac{\text { Jumlah Produk }}{\text { Banyak produk dalam } 1 \text { area }}=\frac{1430}{50}=29$ Area

\section{Data Kapasitas Penyimpanan Rak Awal Gudang}

Tabel 5 menunjukkan penyimpanan yang dilakukan di PT. X yang terdiri dari 5 rak penyimpanan. Setiap rak memiliki jumlah pallet yang berbeda dan pada setiap pallet terdapat jumlah produk yang berbeda.
Tabel 5. Data Penyimpanan Rak Awal PT. X

\begin{tabular}{ccccc}
\hline No & $\begin{array}{c}\text { No. } \\
\text { Rak }\end{array}$ & $\begin{array}{c}\text { Nama } \\
\text { Produk }\end{array}$ & $\begin{array}{c}\text { Jumlah } \\
\text { Pallet/ } \\
\text { rak }\end{array}$ & $\begin{array}{c}\text { Jumlah } \\
\text { Produk/ } \\
\text { pallet }\end{array}$ \\
\hline 1 & $2 \mathrm{~A} 1$ & Baut & 278 & 27800 \\
2 & $2 \mathrm{~A} 2$ & Safety belt & 242 & 24200 \\
3 & A23 & Setir & 231 & 23199 \\
4 & $2 \mathrm{~A} 4$ & Spion & 225 & 22500 \\
5 & $2 \mathrm{~A} 5$ & Lampu & 234 & 23400 \\
\hline \multicolumn{5}{c}{ TOTAL } \\
\hline
\end{tabular}

Sumber: PT. X

\section{Peletakan Area Penyimpanan}

Setelah mengetahui kebutuhan ruangan maka dapat ditentukan yaitu $93 \mathrm{~m}^{2}$, jumlah area yang dapat diperoleh luas gudang adalah $100 \mathrm{~m}^{2}$ x $15 \mathrm{~m}^{2}=1500 \mathrm{~m}^{2}$. Maka dapat diatur bagaimana susunan peletakan area penyimpanan pada gudang berdasarkan data kebutuhan ruang (lebar gudang dan luas area penyimpanan).Tabel 6. menunjukan jarak penyimpanan produk ke pintu pada PT. X.

Tabel 6. Peletakan Area Penyimpanan di PT. X

\begin{tabular}{llc} 
No & Produk & Area Penyimpanan $(\mathbf{m})$ \\
\hline 1 & Baut & 56 \\
2 & Safety belt & 43 \\
3 & Setir & 53 \\
4 & Spion & 38 \\
5 & Lampu & 31 \\
\hline \multicolumn{2}{l}{ Sumber: PT. X }
\end{tabular}

Dari tabel 6 dapat terlihat bahwa, produk baut disimpan paling jauh dari pintu Gudang pada PT. X. Desai dari tata letak Gudang penyimpanan PT. XTZ terlihap pada Gambar. 4.

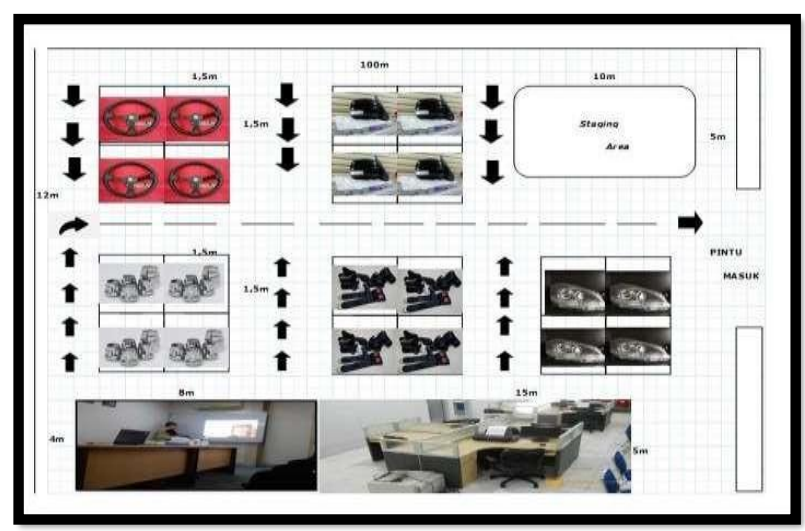

Gambar 4. Layout Gudang PT. X

\section{Data Kapasitas Penyimpanan Rak Baru}

Setelah dilakukan perhitungan terdapat penambahan rak usulan yang pada awalnya hanya terdapat 5 rak dan pada tabel diatas diusulkan penambahan 2 rak. Pada penambahan rak tersebut pallet yang digunakan juga bertambah yag pada awalnya pallet sebanyak 1210 . 
Setelah penambahan rak maka pallet yang digunakan sebanyak 3234 pallet dapat dilihat pada Tabel 7. Masing-masing rak dibuat jadi 2 bagian agar lebih efektif dan mudah melakukan pencarian produk apabila dipesan. Serta area safety awareness dipindahkan dibelakang office karena ruangan tersebut efektif digunakan 1 bulan sekali.

Tabel 7. Penyimpanan Rak Baru

\begin{tabular}{cccc}
\hline No. Rak & Produk & $\begin{array}{c}\text { Jumlah } \\
\text { Pallet/rak }\end{array}$ & $\begin{array}{c}\text { Jumlah } \\
\text { Produk/pallet }\end{array}$ \\
2A1-2A2 & Baut & 487 & 48700 \\
2B1-2B2 & Baut & 453 & 45300 \\
2C1-2C2 & Setir & 424 & 42400 \\
2D1-2D2 & Setir & 436 & 43600 \\
2E1-2E2 & Safety Belt & 434 & 43400 \\
2F1-2F2 & Spion & 531 & 53100 \\
2G1-2G2 & Lampu & 469 & 46900 \\
\hline \multicolumn{3}{c}{ TOTAL } & 3234 \\
\hline \multicolumn{4}{c}{} \\
\hline
\end{tabular}

Layout usulan setelah dilakukan penambahan rak dan pengaturan no rak untuk masing-masing produk terlihat pada Gambar 5.

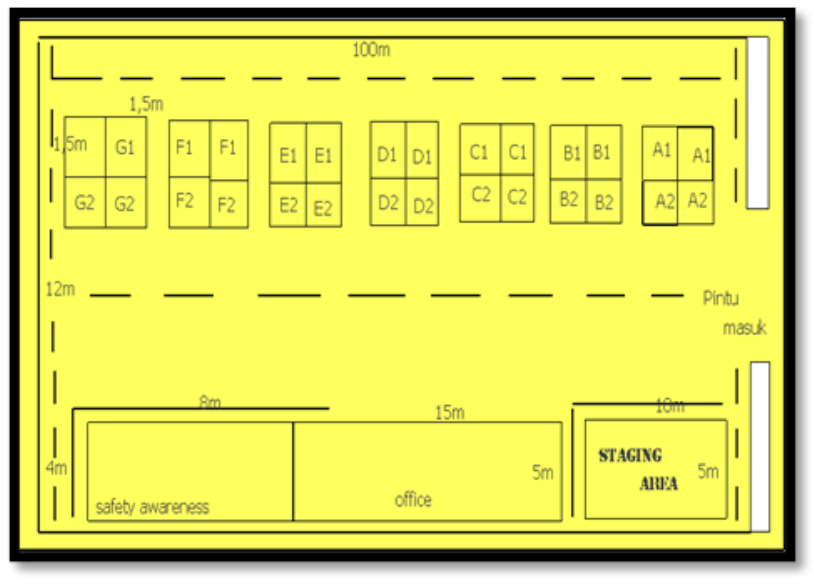

Gambar 5. Layout Usulan

Pada layout usulan, ditambahkan 2 rak untuk mengoptimalkan Gudang agar lebih efektif dan memudahkan proses pancarian barang. Hal ini juga ditujukan untuk menampung, produk dengan permintaan yang besar seperti baut, maka ditempatkan dekat dengan pintu Gudang. Pada layout usulan juga diberikan jalur tengah untuk mempermudah proses put away dan memudahkan untuk mengambil produk.

\section{Jarak Area Penyimpanan ke Pintu}

Penempatan area berdasarkan berdasarkan jenis poduk yang memiliki rata-rata frekuensi tertinggi atau produk yang sering keluar didekatkan dengan pintu masuk dan keluar. Jarak tempuh antara material handling adalah mulai dari pintu (I/O) menuju ke area penyimpanan perhitungan jarak dilakukan dengan menggunakan metode rectilinear distance. Jarak diukur sepanjang lintasan dengan menggunakan garis tegak lurus (orgotonal) satu dengan yang lainnya terhadap titikdari masing-masing area penyimpanan dengan rumus:

$\left.d i j=\sqrt{x-a)^{2}+(y-b}\right)^{2}$

Keterangan:

$\mathrm{D}_{\mathrm{ij}}=$ jarak slot ij ke titik I/O

$\mathrm{X}=$ titik awal perhitungan $\mathrm{I} / \mathrm{O}$ pada sumbu $x$

(horizontal)

$\mathrm{A}=$ jarak titik tengah tujuan terhadap sumbu $\mathrm{x}$

$\mathrm{Y}=$ titik awal perhitungan I/O pada sumbu y (vertical)

$\mathrm{B}=$ jarak titik tengah tujuan terhadap sumbu $\mathrm{y}$

Hasil dari perhitungan jarak penyimpanan ke pintu terlihat pada Tabel 8 .

Tabel 8. Jarak Penyimpanan ke Pintu

\begin{tabular}{ccc}
\hline No & Penyimpanan Area & Jarak (m) \\
\hline 1 & $2 \mathrm{~A} 1$ & 3 \\
2 & $2 \mathrm{~A} 2$ & 4 \\
3 & $2 \mathrm{~B} 1$ & 6 \\
4 & $2 \mathrm{~B} 2$ & 5 \\
5 & $2 \mathrm{C} 1$ & 11 \\
6 & $2 \mathrm{C} 2$ & 10 \\
7 & $2 \mathrm{D} 1$ & 16 \\
8 & $2 \mathrm{D} 2$ & 15 \\
9 & $2 \mathrm{E} 1$ & 21 \\
10 & $2 \mathrm{E} 2$ & 20 \\
11 & $2 \mathrm{~F} 1$ & 26 \\
12 & $2 \mathrm{~F} 2$ & 25 \\
13 & $2 \mathrm{G} 1$ & 31 \\
14 & $2 \mathrm{G} 2$ & 30 \\
\hline
\end{tabular}

Dengan adanya penyusunan usulan bisa memudahkan pihak gudang untuk pengambilan produk yang jumlah permintaannya yang relatif banyak karena sudah di alokasikan secara berurutan serta tidak memakan banyak waktu selama proses pengampilan produk serta kerja warehouse/operator gudang akan lebih efisen. Hal ini sejalan dengan penelitian yang dilakukan oleh Firmansyah \& Lukmandono yang menemukan bahwa pengaturan jarak penyimpanan dapat meminimasi waktu perpindahan [1].

\section{KESIMPULAN}

Berdasarkan hasil pembahasan maka didapatkan beberapa kesimpulan sebagai berikut:

1. Setelah mengusulkan rancangan layout baru pada gudang maka dapat perhitungan yang dilakukan yaitu jumlah rak ditambah dan rak diberi nomor sesuai dengan jenis produk, serta posisi rak harus sejajar dan penambahan 2 rak penyimpanan. Penyimpanan kapasitas penyimpanan awalnya hanya 1210 pallet. Setelah dilakukan penyimpanan rak

62 Candrianto et al. 
baru menjadi 3234 pallet.

2. Pada layout lama terdapat penyimpanan 5 rak penyimpanan. Setelah dilakukan perhitungan terdapat penambahan kapasitas rak dan disusun dalam satu nomor yang terdiri dari 2 bagian penyimpanan yaitu 2A1, 2A2, 2B1, 2B2, 2C1, 2C2, 2D1, 2D2, 2E1, 2E2, 2F1, 2F2, 2G1, 2G2. Barang yang banyak permintaannya didekatkan ke pintu penyimpanan supaya memudahkan pengambilan barang outbound.

3. Keuntungan metode shared storage di gudang PT. X yaitu mengubah beberapa jenis produk yang di simpan secara berurutan karena setiap area penyimpanan bisa saja ditempati oleh beberapa jenis produk yang berbeda-beda berdasarkan waktu permintaan dan permintaan produk yang jumlahnya relatif banyak.

\section{DAFTAR PUSTAKA}

[1] A. Firmansyah and L. Lukmandono, "Warehouse Relayout Design with Weighted Distance Method to Minimize Time Travel," Petra Int. J. Bus. Stud., vol. 3, no. 1, pp. 1-8, 2020, doi: 10.9744/ijbs.3.1.1-8.

[2] A. P. Sujana, D. D. Damayanti, and M. D. Astuti, "Metode Class Based Storage Pada Gudang Bahan Baku 1 Pt Sma,” vol. 1, pp. 1-7, 2014.

[3] H. Jay and R. Barry, Manajemen Operasi : Manajemen keberlangsungan Rantai Pasokan Edisi 11, Indonesia: Salemba 4, 2016

[4] H. M. Nur and V. Maarif, "Perencanaan Tata Letak Gudang Menggunakan Metode ClassBased Storage-Craft Pada Distributor Computer \& Office Equipment," Evolusi J. Sains dan Manaj., vol. 6, no. 2, pp. 36-42, 2018, doi: 10.31294/evolusi.v6i2.4425.

[5] L. Liana, "Penentuan Tata Letak Ruang Menggunakan Weighted-Distance Method di CV . Sumber Technik," Din. Tek., vol. X, pp. 27-39, 2017.

[6] M. Zaenuri, "Evaluasi Perancangan Tata Letak Gudang Menggunakan Metode Shared Storage Di Pt . International Premium Pratama Surabaya," Matrix, vol. XV, no. 2, pp. 21-36, 2015.

[7] P. Moengin, I. N. Firdaus, and S. Adisuwiryo, "Perancangan Model Simulasi Tata Letak Gudang Bahan Baku untuk Meminimasi Waktu Pengambilan Bahan Baku Pada PT . Springville Indonesia dengan Menggunakan Metode Dedicated Storage," vol. 8, no. 1, pp. 115-132, 2018.

[8] Richard L. Francis, Leon F. McGinnis, Jr., \&
John A. White, Facility Layout And Location: An Analytical Approach, edisi ke 2. Prentice Hall International Series in Industrial and System Engineering, New Jersey, 1992

[9] S. Assauri, Manajemen Operasi dan Produksi, Indonesia: Fakultas Ekonomi Universitas Indonesia, 2008

[10] Sutarman, Dasar-Dasar Manajemen Logistik, Bandung: Refika Aditama, 2017.

[11] William, "Perancangan Tata Letak Gudang Produk Jadi Pada Pt. Bioli Lestari Surabaya," J. Ilm. Mhs. Univ. Surabaya Vol.6 No.2 (2017)911, vol. 6, no. 2, pp. 910-920, 2017, [Online].

Available: http://webhosting.ubaya.ac.id/ journalubayaac/i ndex.php/jimus/article/view/965/772. 